SANTOS, A.L.Q. et al. Estudo anatomo-topográfico do tubo digestório das espécies Athene cunicularia (Strigiformes, Strigidae) e Tyto alba (Strigiformes, Tytonidae). PUBVET, Londrina, V. 6, N. 12, Ed. 199, Art. 1334, 2012.

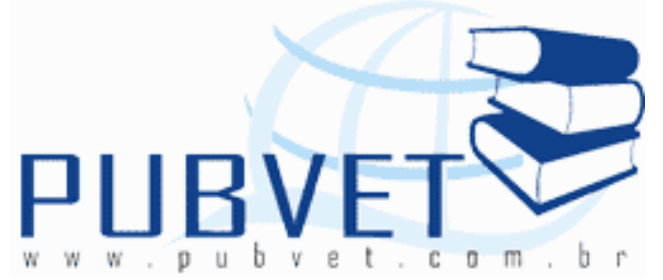

PUBVET, Publicações em Medicina Veterinária e Zootecnia.

\title{
Estudo anatomo-topográfico do tubo digestório das espécies Athene cunicularia (Strigiformes, Strigidae) e Tyto alba (Strigiformes, Tytonidae)
}

André Luiz Quagliatto Santos ${ }^{1}$, Mariana Batista Andrade ${ }^{3}$, Árthur Paulino Sanzo Kaminishi $^{2}$, Lorena Tannús Menezes ${ }^{2}$, Rogério Rodrigues de Souza ${ }^{2}$, Caio Henrique Ferreira ${ }^{2}$, Sérgio Rodrigo Pereira de Oliveira ${ }^{2}$, Liliane Rangel Nascimento ${ }^{2}$, Flávio Machado de Moraes ${ }^{1}$

Laboratório de Ensino e Pesquisa em Animais Silvestres - LAPAS, FAMEV/UFU, e-mail: quagliatto@famev.ufu.br 1. Docente. 2. Mestrandos. 3. Doutoranda.

\section{Resumo}

O aparelho digestório é o "compartimento" do organismo responsável pela manutenção da vida, sendo o tubo digestório de cada ave adaptado para processar e utilizar o mais eficientemente possível o alimento disponível em seu habitat. Com o intuito de se ampliar os conhecimentos anatômicos relativos ao tubo digestório das aves, abordou-se em um estudo anatomotopográfico, quatro exemplares de aves, representantes da ordem Strigiformes, doadas pelo IBAMAUberlândia/MG. No Laboratório de Pesquisa em Animais Silvestres (LAPAS) da UFU os animais foram fotografados, identificadas quanto ao gênero e espécie e dissecadas, com a finalidade de se obter informações relativas à topografia, forma e dimensões dos segmentos do tubo digestório. Ao final da pesquisa foram 
SANTOS, A.L.Q. et al. Estudo anatomo-topográfico do tubo digestório das espécies Athene cunicularia (Strigiformes, Strigidae) e Tyto alba (Strigiformes, Tytonidae). PUBVET, Londrina, V. 6, N. 12, Ed. 199, Art. 1334, 2012.

observadas algumas diferenças relativas à topografia, dimensões e composição do tubo digestório. Características observadas de maior relevância incluem ausência de inglúvio e presença de cecos desenvolvidos.

Palavras-chave: coruja, esôfago, estômago, intestino.

\title{
Anatomo-topographic study of the digestive tract of the species Athene cunicularia (Strigiformes, Strigidae) and Tyto alba (Strigiformes, Tytonidae)
}

\begin{abstract}
The digestive system is the "compartment" of the body responsible for the maintenance of life, and the digestive tract of each bird adapted to process and utilize as efficiently as possible the food available in their habitat. In order to broaden the knowledge regarding the anatomical digestive tract of birds, was addressed in a study Anatomotopographic, four copies of birds, representatives of the order Strigiformes, donated by IBAMA, Uberlândia / MG. In the Research Laboratory of Wild Animals (LAPAS) UFU of the animals were photographed, identified as to genus and species and dissected for the purpose of obtaining information on topography, shape and dimensions of the segments of the digestive tract. At the end of the study were observed some differences in the topography, size and composition of the digestive tract. Most relevant features observed include lack of ingluvio and presence of developed caecum.
\end{abstract} Keywords: Owl, esophagus, stomach, intestine.

\section{INTRODUÇÃO}

A criação de aves silvestres em cativeiro e o crescente hábito de mantê-las como animais de companhia têm incentivado inúmeros profissionais e 
SANTOS, A.L.Q. et al. Estudo anatomo-topográfico do tubo digestório das espécies Athene cunicularia (Strigiformes, Strigidae) e Tyto alba (Strigiformes, Tytonidae). PUBVET, Londrina, V. 6, N. 12, Ed. 199, Art. 1334, 2012.

pesquisadores a buscar conhecimentos sobre as diferenças de ordem anatômica, fisiológica, comportamental e metabólica existentes entre as mesmas (NICOLAU et al., 2002).

Em geral, o tubo digestório das aves domésticas está muito bem descrito anatomicamente por diversos autores, dos quais alguns fazem comentários superficiais, de tom comparativo e de maneira generalizada ao abordar o assunto em outras aves. Por exemplo, McLelland (1986) compara o tamanho dos estômagos do pato e ganso em relação ao da galinha e Malewitz e Calhoun (1958) apud McLelland (1986) relatam que a dimensão do trato intestinal do peru é comparável ao da galinha.

O sistema gastrointestinal constitui-se em habitat para diversos parasitos, como Ascaridia sp, Coccicidios e Strongyloides, os quais dentre outros representam especial risco para aves silvestres mantidas em cativeiro sob estresse, nutrição inadequada e as que apresentam enfermidades sistêmicas (FREITAS et al., 2002; BARTON; HOUSTON, 2001).

Aspectos como anatomia gastrointestinal, fisiologia digestiva, potencialidades bioquímicas e microflora comensal aliadas às preferências dietéticas da ave são estratégicos no estabelecimento de uma dieta nutricionalmente adequada (KLASING, 2005).

Alguns autores sustentam a existência de uma relação entre os aspectos anatômicos dos órgãos digestórios e os hábitos alimentares da ave em questão, a exemplo de Deen e Bennett (1996). De acordo com Macari, Furlan e Nakaghi (1994), a ingestão de alimentos é largamente determinada pelas características anatomofisiológicas e pela capacidade do trato digestório.

Segundo Duke (1996), o volume e o comprimento do trato digestório variam consideravelmente entre as espécies, dependendo sobretudo dos hábitos alimentares. Por exemplo, aves carnívoras e piscívoras precisam expandir as áreas de estocagem para acomodar grande volume de alimento mole. Já as que 
SANTOS, A.L.Q. et al. Estudo anatomo-topográfico do tubo digestório das espécies Athene cunicularia (Strigiformes, Strigidae) e Tyto alba (Strigiformes, Tytonidae). PUBVET, Londrina, V. 6, N. 12, Ed. 199, Art. 1334, 2012.

comem insetos ou sementes precisam de um órgão muscular responsável pela trituração do alimento (POUGH; HEISER; McFARLAND, 1999).

Um exemplo importante envolvendo a função da anatomia topográfica como método auxiliar na clínica e cirurgia foi citado por Duke (1996), enfatizando que o esôfago e o papo são freqüentemente acometidos por corpos estranhos e impactação. Ainda segundo este autor, por serem palpáveis devido à sua localização subcutânea, possuem fácil acesso cirúrgico.

O conhecimento de particularidades anatômicas do tubo digestório das diferentes espécies é imprescindível na interpretação correta e completa das imagens radiográficas de uma ave (SMITH; SMITH, 1997), bem como na execução de procedimentos de rotina e intervenções cirúrgicas. Também representa um fator determinante na nutrição adequada principalmente de aves mantidas em cativeiro ou como animais de companhia. Logo, propôs-se realizar uma descrição anatômica do tubo digestório de aves da ordem Strigiformes, enfocando as principais características topográficas e particularidades anatômicas dos representantes.

\section{MATERIAL E MÉTODOS}

Este estudo foi realizado utilizando-se quatro aves, de duas espécies, representantes da ordem Strigiformes doadas pelo IBAMA - Uberlândia-MG.

Os exemplares foram enviados congelados ao Laboratório de Pesquisa em Animais Silvestres (LAPAS) da Faculdade de Medicina Veterinária da UFU onde foram fotografados, de modo a enfatizar aspectos individuais que diferenciam as espécies.

A identificação das aves incluiu sua classificação quanto à ordem, gênero e espécie, e foi realizada com auxílio de Accioly (2000), Souza (1998) e Juniper e Pan (1998). 
SANTOS, A.L.Q. et al. Estudo anatomo-topográfico do tubo digestório das espécies Athene cunicularia (Strigiformes, Strigidae) e Tyto alba (Strigiformes, Tytonidae). PUBVET, Londrina, V. 6, N. 12, Ed. 199, Art. 1334, 2012.

As duas espécies trabalhadas foram Athene cunicularia, com três exemplares, e Tyto alba com um exemplar.

Cada exemplar, depois de submetido ao processo completo de dissecação e registro das informações relevantes, foi conservado em solução de formaldeído a $10 \%$ injetada em toda a musculatura das aves com seringas descartáveis de $5 \mathrm{ml}$ e agulha descartável de $13 \times 0,45 \mathrm{~mm}$.

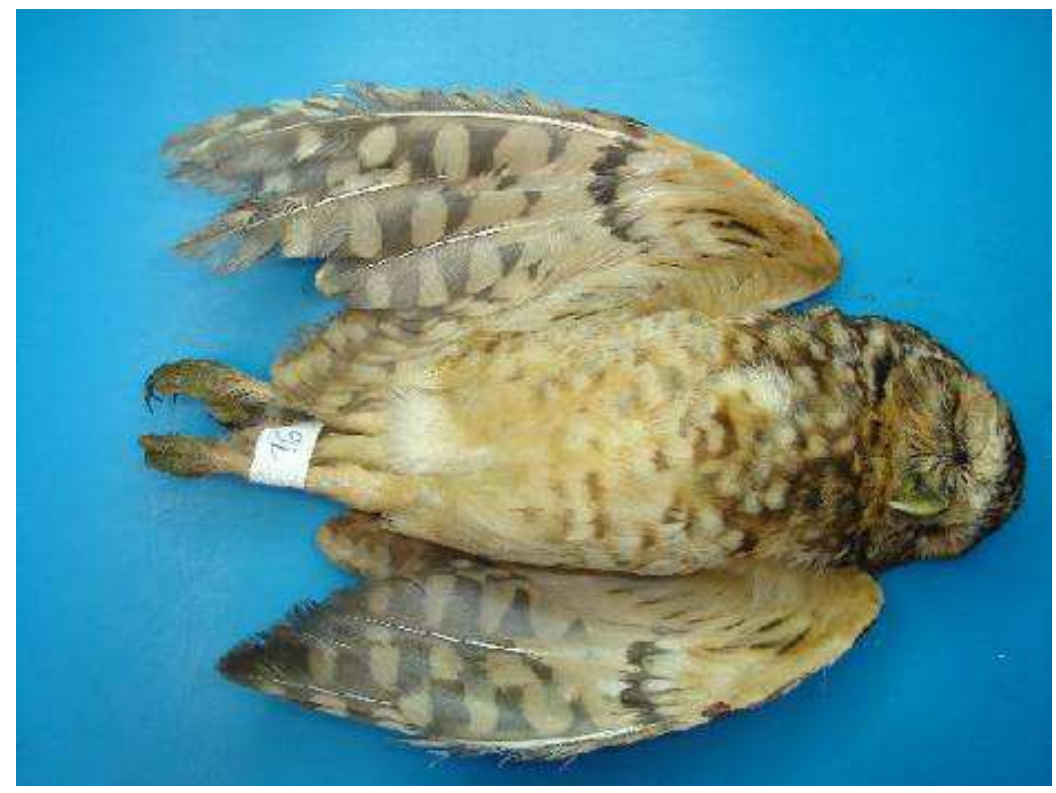

Fotografia 01 : Coruja-buraqueira Athene cunicularia Molina, 1782 (STRIGIDAE). 
SANTOS, A.L.Q. et al. Estudo anatomo-topográfico do tubo digestório das espécies Athene cunicularia (Strigiformes, Strigidae) e Tyto alba (Strigiformes, Tytonidae). PUBVET, Londrina, V. 6, N. 12, Ed. 199, Art. 1334, 2012.

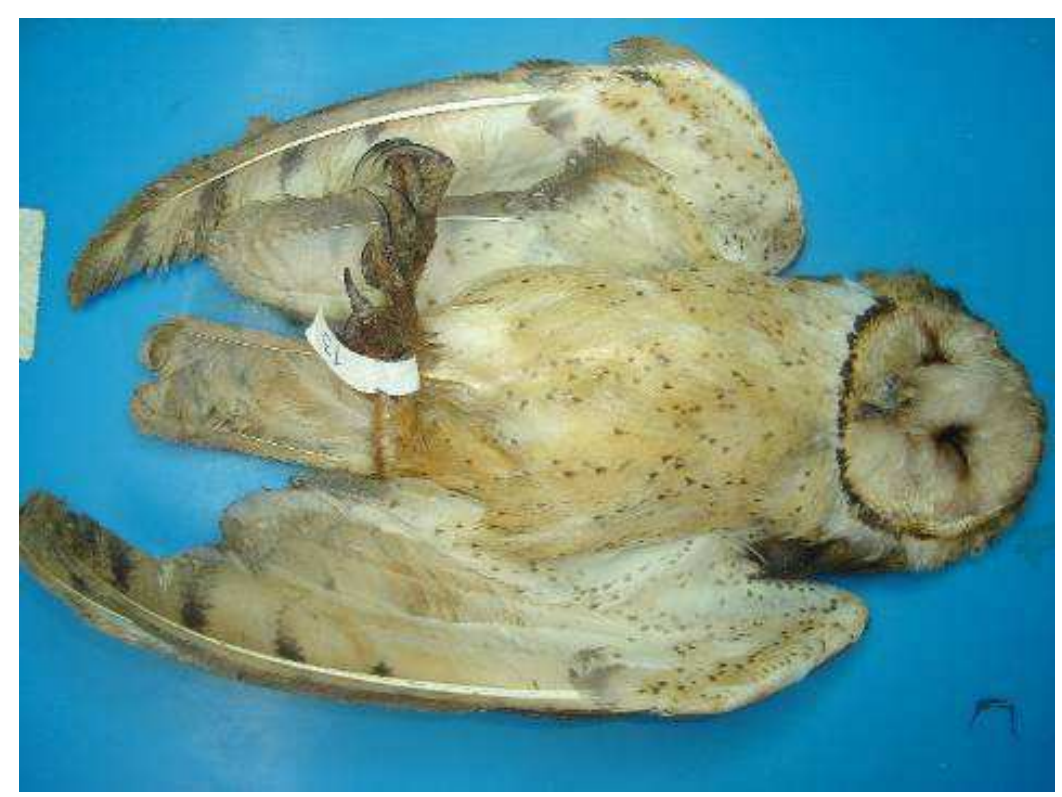

Fotografia 02: suindara Tyto alba Scopoli, 1769 (TYTONIDAE).

Cada ave foi dissecada a fresco, com a finalidade de manter os órgãos em suas dimensões originais, obtendo-se medidas de comprimento e diâmetro com mínima margem de erro. Concomitantemente, procedeu-se à descrição e elaboração de desenhos esquemáticos e fotografias enfocando características relativas a dimensionamento, topografia, morfologia e composição do tubo digestivo.

O comprimento total de cada ave, que consiste na distância entre a extremidade rostral do bico até a extremidade caudal da última pena da cauda, foi obtido com o animal em decúbito dorsal e com o pescoço estendido. As corujas-buraqueiras (Athene cunicularia) foram identificadas como 01, macho, com 21,70 cm de comprimento; 02, fêmea, com 24,20 cm de comprimento; e 03, macho, com 22,30 cm de comprimento. Já a suindara (Tyto alba), fêmea, apresentou $32,90 \mathrm{~cm}$ de comprimento.

Com o auxílio de um cabo de bisturi no 4, uma lâmina para bisturi no 23, uma pinça Adson e uma pinça anatômica, procedeu-se a abertura da cavidade 
SANTOS, A.L.Q. et al. Estudo anatomo-topográfico do tubo digestório das espécies Athene cunicularia (Strigiformes, Strigidae) e Tyto alba (Strigiformes, Tytonidae). PUBVET, Londrina, V. 6, N. 12, Ed. 199, Art. 1334, 2012.

toracoabdominal de cada exemplar a partir de uma incisão na linha mediana ventral (delimitada pelo osso esterno e cloaca) e posterior retirada do quilha.

Foram adotados os seguintes pontos de referência para descrição anatômica e mensuração dos segmentos do tubo digestivo:

Esôfago cervical: início na laringe e término na entrada da cavidade toracoabdominal;

- Inglúvio: início na região de dilatação do esôfago cervical e término na extremidade cranial do esôfago torácico;

Esôfago torácico: início na entrada da cavidade e término na junção com o proventrículo;

Proventrículo: início na união com esôfago torácico e término na divisão com o ventrículo ou no istmo, quando presente;

- Ventrículo: início na união com o proventrículo e término no início da alça descendente do duodeno;

- $\quad$ Alça descendente do duodeno: início no piloro e término na curvatura de união com a alça ascendente do duodeno;

- Alça ascendente do duodeno: início na união com a alça anterior e término na curvatura de união ao segmento jejunoilíaco;

Jejuno-íleo: início na união com o segmento anterior e término na divisão com coloreto, considerando-se a presença de cecos, quando existirem;

- $\quad \operatorname{Ceco(s):~do~seu~ponto~de~inserção~no~segmento~intestinal~ao~seu~}$ ápice;

- Coloreto: início na base do(s) $\operatorname{ceco}(\mathrm{s})$, quando existirem ou do momento em que se desfazem as alças que compõem o segmento jejunoilíaco e término na cloaca;

Após descrição topográfica, o tubo digestivo foi individualizado com o auxílio de uma pinça anatômica, uma pinça hemostática, uma pinça dente de 
SANTOS, A.L.Q. et al. Estudo anatomo-topográfico do tubo digestório das espécies Athene cunicularia (Strigiformes, Strigidae) e Tyto alba (Strigiformes, Tytonidae). PUBVET, Londrina, V. 6, N. 12, Ed. 199, Art. 1334, 2012.

rato, uma tesoura Mayo curva e uma tesoura Metzembaum reta, divulsionando-se os tecidos que mantinham os segmentos do tubo digestivo relacionado a outros órgãos.

Cada órgão foi mensurado com um paquímetro Starret de precisão 0,05 $\mathrm{mm}$, de modo a registrar o comprimento e diâmetro dos mesmos. As medidas de diâmetro tomadas não se apresentam de maneira constante para todas as aves, uma vez que variaram de acordo com o estado de distensão do órgão no momento do óbito da ave.

Estabeleceu-se uma relação, em porcentagem média, entre o comprimento de cada segmento do tubo digestivo e o comprimento total dos exemplares de uma mesma ordem.

\section{RESULTADOS}

Quadro 01: Medidas de comprimento e diâmetro, dos órgãos do tubo digestivo de suindara, $\mathrm{n}^{\circ} 01$.

\begin{tabular}{|c|c|c|}
\hline Órgão & Comprimento (mm) & Diâmetro (mm) \\
\hline Esôfago cervical & 78,75 & 14,15 \\
\hline Esôfago torácico & 39,30 & 8,70 \\
\hline Proventrículo & 23,80 & 8,55 \\
\hline Ventrículo * & \multicolumn{2}{|c|}{$21,55 \times 19,00 \times 8,45$} \\
\hline Alça descendente do duodeno & 49,20 & 5,85 \\
\hline Alça ascendente do duodeno & 56,80 & 6,60 \\
\hline Jejuno-íleo & 243,35 & 5,80 \\
\hline Ceco direito & 44,10 & 5,95 \\
\hline Ceco esquerdo & 51,00 & 8,85 \\
\hline Coloreto & 22,80 & 9,85 \\
\hline
\end{tabular}


SANTOS, A.L.Q. et al. Estudo anatomo-topográfico do tubo digestório das espécies Athene cunicularia (Strigiformes, Strigidae) e Tyto alba (Strigiformes, Tytonidae). PUBVET, Londrina, V. 6, N. 12, Ed. 199, Art. 1334, 2012.

Quadro 02: Comprimento e diâmetro dos componentes do tubo digestivo de um exemplar coruja-buraqueira, $\mathrm{n}^{\circ} 01$.

\begin{tabular}{|l|c|c|}
\hline Órgão & Comprimento (mm) & Diâmetro (mm) \\
\hline Esôfago cervical & 36,95 & 6,70 \\
\hline Esôfago torácico & 33,85 & 4,90 \\
\hline Proventrículo & 14,55 & 8,40 \\
\hline Ventrículo * & \multicolumn{2}{|c|}{$17,90 \times 16,00 \times 11,70$} \\
\hline Alça descendente do duodeno & 39,30 & 4,05 \\
\hline Alça ascendente do duodeno & 44,25 & 4,80 \\
\hline Jejuno-íleo & 148,20 & 4,30 \\
\hline Ceco direito & 32,70 & 5,85 \\
\hline Ceco esquerdo & 31,50 & 32,70 \\
\hline Coloreto & 20,00 & 3,80 \\
\hline
\end{tabular}

* Comprimento X Largura X Espessura

Quadro 03: Comprimento e diâmetro dos componentes do tubo digestivo de um exemplar coruja-buraqueira, no 02.

\begin{tabular}{|l|l|l|}
\hline Órgão & Comprimento (mm) & Diâmetro (mm) \\
\hline Esôfago cervical & 37,95 & 5,30 \\
\hline Esôfago torácico & 27,50 & 3,55 \\
\hline Proventrículo & 18,75 & 10,35 \\
\hline Ventrículo * & $23,25 \times 14,60 \times 12,70$ \\
\hline Alça descendente do duodeno & 49,15 & 5,90 \\
\hline Alça ascendente do duodeno & 59,40 & 5,70 \\
\hline Jejuno-íleo & 222,45 & 4,90 \\
\hline Ceco direito & 38,50 & 4,70 \\
\hline Ceco esquerdo & 35,85 & 3,90 \\
\hline Coloreto & 41,60 & 4,35 \\
\hline
\end{tabular}


SANTOS, A.L.Q. et al. Estudo anatomo-topográfico do tubo digestório das espécies Athene cunicularia (Strigiformes, Strigidae) e Tyto alba (Strigiformes, Tytonidae). PUBVET, Londrina, V. 6, N. 12, Ed. 199, Art. 1334, 2012.

Quadro 04: Comprimento e diâmetro dos componentes do tubo digestivo de um exemplar coruja-buraqueira, $\mathrm{n}^{\circ} 03$.

\begin{tabular}{|l|l|l|}
\hline Órgão & Comprimento (mm) & Diâmetro (mm) \\
\hline Esôfago cervical & 40,20 & 4,80 \\
\hline Esôfago torácico & 25,00 & 4,90 \\
\hline Proventrículo & 17,80 & 8,95 \\
\hline Ventrículo $*$ & $15,95 \times 24,70 \times 16,60$ \\
\hline Alça descendente do duodeno & 55,00 & 5,60 \\
\hline Alça ascendente do duodeno & 71,10 & 4,40 \\
\hline Jejuno-íleo & 167,80 & 4,50 \\
\hline Ceco direito & 39,95 & 4,85 \\
\hline Ceco esquerdo & 29,75 & 4,50 \\
\hline Coloreto & 36,40 & 4,35 \\
\hline \multicolumn{2}{|l|}{$*$ Comprimento X Largura X Espessura } & \\
\hline
\end{tabular}

O esôfago cervical inicia-se dorsalmente à traquéia, na face ventral do pescoço e logo no terço inicial do mesmo se desvia para o antímero direito, mantendo toda sua trajetória dorsolateralmente à traquéia até a cavidade tóracoabdominal, quando se une à porção torácica, haja visto a ausência de inglúvio. Representa em média, 18,66\% do comprimento total das aves.

O esôfago torácico segue dorsolateralmente à traquéia, dorsalmente à siringe, bifurcação traqueal e base do coração e ventralmente aos lobos pulmonares, unindo-se ao proventrículo à nível do terço proximal do coração e extremidade cranial do lobo hepático esquerdo, ao qual está dorsalmente relacionado. Equivale em média, a $12,52 \%$ do comprimento total dos representantes.

O estômago químico é cilíndrico, e representa em média $7,41 \%$ do comprimento total das aves. Está localizado em posição paramediana esquerda na cavidade, ventralmente aos lobos pulmonares, havendo maior contato com 
SANTOS, A.L.Q. et al. Estudo anatomo-topográfico do tubo digestório das espécies Athene cunicularia (Strigiformes, Strigidae) e Tyto alba (Strigiformes, Tytonidae). PUBVET, Londrina, V. 6, N. 12, Ed. 199, Art. 1334, 2012.

lobo esquerdo. Relaciona-se a porção craniomedial do lobo hepático direito através de sua face lateral direita.

A união entre o proventrículo e estômago muscular ocorre paralelamente ao ovário na fêmea e do testículo no macho.

O ventrículo está localizado dorsalmente ao emaranhado de alças intestinais, no antímero esquerdo da cavidade. Em suindara, o maior eixo está disposto obliquamente (do antímero esquerdo para o direito). Sua face dorsolateral direita está em contato com grande parte dos cecos (exceto a base), que ascendem da transição entre jejuno-íleo e coloreto. A porção cranial de sua face ventral está relacionada à porção caudal dos lobos hepáticos. Equivale em média, a 7,88\% do comprimento total dos representantes.

A porção cranial do duodeno está situada dorsalmente ao terço caudal do lobo hepático direito.

Inicia-se na face craniolateral direita da moela, através da alça descendente do duodeno, que segue caudolateralmente contornando a moela e termina à nível da borda caudal da mesma, onde une-se à porção ascendente, através de uma curva cranial. Em suindara, a alça descendente do duodeno segue caudolateralmente em direção ao antímero esquerdo, até encostar na parede da cavidade, onde une-se à alça ascendente do duodeno. Representa em média, $19,50 \%$ do comprimento total das aves.

A alça ascendente do duodeno segue trajetória oposta, dorsalmente ao segmento descendente e une-se ao jejuno-íleo caudalmente à vesícula biliar através de uma curva projetada dorsocaudalmente. Equivale em média, a $22,17 \%$ do comprimento total das aves.

Jejuno-íleo localiza-se predominantemente no antímero direito da cavidade, dorsalmente ao duodeno e parte do ventrículo, sob o rim direito. O segmento próximo aos cecos está unido à face dorsal da alça duodenal por mesentério. É o 
SANTOS, A.L.Q. et al. Estudo anatomo-topográfico do tubo digestório das espécies Athene cunicularia (Strigiformes, Strigidae) e Tyto alba (Strigiformes, Tytonidae). PUBVET, Londrina, V. 6, N. 12, Ed. 199, Art. 1334, 2012.

maior segmento intestinal, equivalente, em média a $77,35 \%$ do comprimento total dos representantes.

O intestino grosso consiste em um par de cecos e coloreto. Os cecos são compridos, de formato cilíndrico até a metade de seu comprimento, e semelhante a uma bolsa até o ápice. Situam-se paralelamente à porção final do intestino delgado. Estão inicialmente direcionados cranialmente. Em seu terço médio, projetam-se acentuadamente para o antímero direito, fazendo uma curva, a partir da qual passam a estar direcionados caudalmente. O ceco esquerdo está unido por mesentério à porção final da alça ascendente do duodeno. $O$ direito, por sua vez, está unido à porção final de jejuno-íleo, é mais cranial e mais comprido que o esquerdo. Em suindara, o ceco esquerdo é mais comprido e mais calibroso que o direito. Equivalem em média, a $14,54 \%$ e $15,56 \%$ do comprimento total dos representantes, respectivamente.

O coloreto segue pelo antímero esquerdo da cavidade, ventralmente aos lobos renais médio e caudal e lateralmente ao oviduto (na fêmea) até a cloaca. Representa em média, $12,41 \%$ do comprimento total das aves.

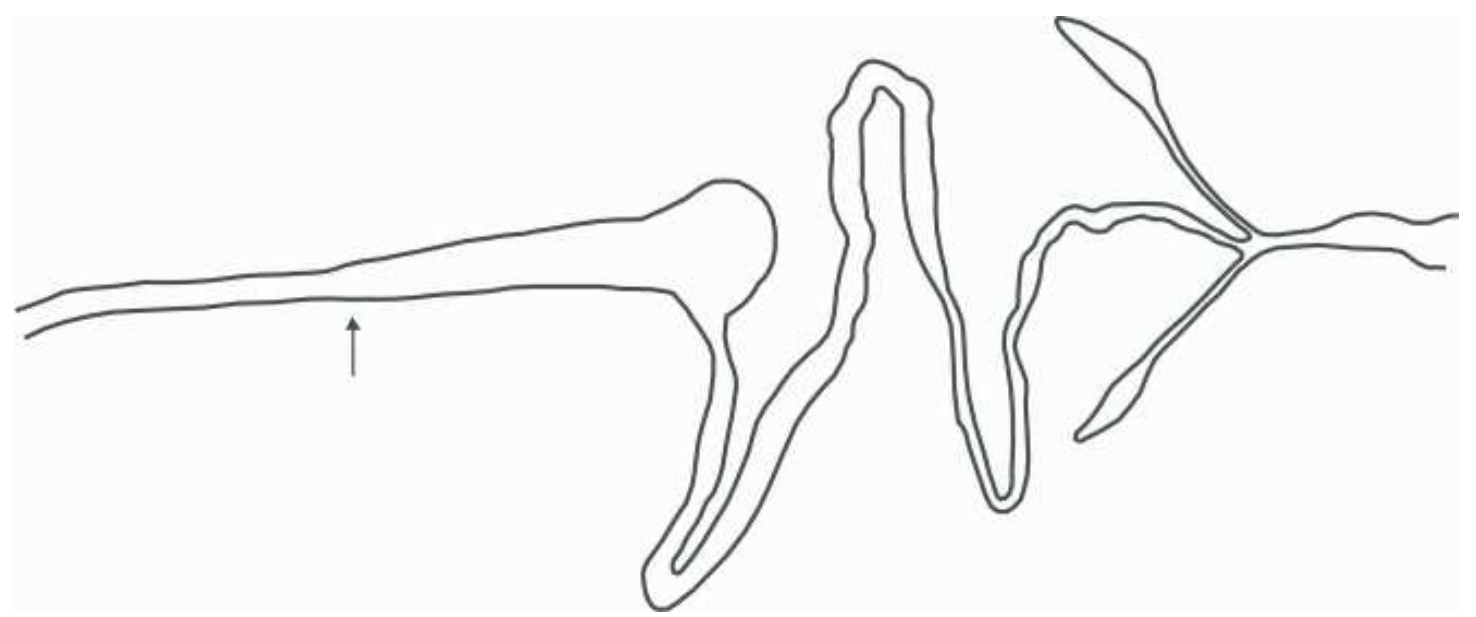

Desenho 01: Representação esquemática do tubo digestório de suindara. Transição entre esôfago cervical e esôfago torácico (seta). 
SANTOS, A.L.Q. et al. Estudo anatomo-topográfico do tubo digestório das espécies Athene cunicularia (Strigiformes, Strigidae) e Tyto alba (Strigiformes, Tytonidae). PUBVET, Londrina, V. 6, N. 12, Ed. 199, Art. 1334, 2012.

\section{DISCUSSÃO}

Barton e Houston (1996) dizem haver uma relação muito próxima do comportamento de caça de aves de rapina e as dimensões de seus órgãos internos. Neste experimento, os achados concordam com os autores, sendo a Tyto alba uma coruja com maior atividade de caça e necessidade de manobras agressivas quando comparada a Athene cunicularia, e entre as duas, houve essa diferença entre volume de órgãos internos em relação ao comprimento total, sendo que a primeira apresentou, proporcionalmente, órgãos menores que a segunda.

Segundo Nickel, Schummer e Seiferle (1977) a porção cervical do esôfago é mais longa que a torácica e em nenhuma das espécies estudadas o esôfago cervical segue pela linha média do pescoço desviando-se caudalmente para o lado direito, como relatou Nickel, Schummer e Seiferle (1977) e Getty (1986) e nem posicionado ventralmente à traquéia (GETTY, 1986).

$\mathrm{Na}$ ordem Strigiformes a porção cervical tem início na face ventral do pescoço e logo no terço inicial desvia-se para o lado direito mantendo-se dorsalmente ou dorsolateralmente à traquéia, concordando com Dyce, Sack e Wensing, (1997). Porém, não é observado a dilatação do inglúvio, sendo este ausente em Strigiformes (DUKE, 1996).

No trabalho de Nickel, Schummer e Seiferle (1977), o esôfago torácico estende-se dorsalmente á traquéia, entre a siringe e a superfície ventral do pulmão até a base do coração e superfície dorsal do fígado coicidindo com nossos resultados. Segundo Getty, o esôfago torácico segue até a face medial do lobo hepático esquerdo, o que mostrou-se correto com relação a ordem estudada.

O estômago é dividido em proventrículo e ventrículo (NICKEL; SCHUMMER; SEIFERLE，1977, MACARI; FURLAN; NAKAGHI, 1994, BENNETT; DEEM, 1996), os 
SANTOS, A.L.Q. et al. Estudo anatomo-topográfico do tubo digestório das espécies Athene cunicularia (Strigiformes, Strigidae) e Tyto alba (Strigiformes, Tytonidae). PUBVET, Londrina, V. 6, N. 12, Ed. 199, Art. 1334, 2012.

quais são anatomicamente e fisiologicamente distintos (NICKEL; SCHUMMER; SEIFERLE, 1977).

O proventrículo é pequeno e situa-se cranialmente ao grande ventrículo, separado do mesmo por uma distinta constriç̧ão, o istmo, como descreveu Getty (1986). Entretanto os dois estômagos apresentam pouca divisão entre si nos Strigiformes. Desta ordem, a maioria inclui aves que se alimentam de grandes presas, nas quais esta característica anatômica está presente, conforme Bennett e Deem (1996). O estômago químico apresenta-se em posição paramediana esquerda, no terço médio da cavidade toracoabdominal, e não no quadrante inferior esquerdo como relatou Getty (1986). Observou-se uma relação do proventrículo com a face ventral do lobo hepático esquerdo em todas as ordens, concordando com o citado por esse autor.

O estômago muscular possui formato arredondado, e o diâmetro do seu eixo craniocaudal é maior que o dorsoventral, conforme relata Getty (1986). Bennett e Deem (1996) relatam a presença do estômago muscular à esquerda da linha média e pode ser palpado imediatamente caudal ao esterno, porém, em Strigiformes, isto não acontece, a face ventral do estômago relaciona-se à superfície dorsal do lobo hepático esquerdo e em parte ao lóbulo direito como o descrito por Nickel, Schummer e Seiferle (1977). Em geral, localiza-se ventralmente às alças intestinais e cecos, nas aves que os possuem e lateralmente à alça duodenal, semelhante ao descrito por Getty (1986). Nas fêmeas relacionam-se também ao ovário (NICKEL; SCHUMMER; SEIFERLE, 1977).

O duodeno é o segmento mais ventral do intestino (DEEM; BENNETT, 1996). Segundo este autor, se estende da porção cranial da face lateral direita do ventrículo, segue caudoventralmente em sua maior parte do lado direito e dorsalmente ao lobo hepático direito, apenas através de sua porção cranial, concordando em parte com a afirmação de Nickel, Schummer e Seiferle (1977).

A união da porção descendente com a porção ascendente do duodeno 
SANTOS, A.L.Q. et al. Estudo anatomo-topográfico do tubo digestório das espécies Athene cunicularia (Strigiformes, Strigidae) e Tyto alba (Strigiformes, Tytonidae). PUBVET, Londrina, V. 6, N. 12, Ed. 199, Art. 1334, 2012.

ocorre através de uma curva dorsal, caudalmente ao estômago muscular, conforme já descrito por Getty (1986).

Segundo Getty (1986), a alça ascendente do duodeno segue imediatamente dorsal à parte descendente, e a maior parte da porção ascendente situa-se próximo ao jejuno, à direita, e ao íleo e ceco esquerdo, dorsalmente, relaciona-se também à superfície dorsal do fígado, testículo direito ou ovário, de acordo com a citação de Nickel, Schummer e Seiferle (1977).

Nickel, Schummer e Seiferle (1977) relatam que a união entre o duodeno e jejuno-íleo ocorre ao nível do lobo renal cranial direito, observado na ordem estudada.

O intestino delgado é dividido em três segmentos distintos, denominados duodeno, jejuno e íleo por Deem e Bennett (1996), Dyce, Sack e Wensing (1997), Getty (1986), Nickel, Schummer e Seiferle (1977), Andrade e colaboradores (2004) e Borges e colaboradores (2004). Ao contrário, este estudo considera apenas dois segmentos distintos denominados duodeno e jejuno-íleo, assim como Souza e colaboradores (2005).

O segmento jejunoilíaco forma alças dispostas em " $U$ ", concordando com Deem e Bennett (1996). Estão dispostas uma sobre a outra, predominantemente no antímero direito da cavidade, como cita Dyce, Sack e Wensing (1997).

É o segmento intestinal mais longo em todas as aves estudadas, conforme o exposto por Nickel, Schummer e Seiferle (1977). Situa-se ventralmente aos rins e dorsalmente ao duodeno e estômago muscular concordando em parte com Getty (1986), já que o duodeno relaciona-se ventralmente com o fígado, e não o segmento jejunoilíaco.

Observou-se que Strigiformes o intestino grosso compreende um par de cecos e o cólon, como relata Nickel, Schummer e Seiferle (1977) e Dyce, Sack e Wensing (1997). Coloreto foi o termo utilizado para denominar o último segmento intestinal, diferindo de Nickel, Schummer e Seiferle (1977) que utiliza 
SANTOS, A.L.Q. et al. Estudo anatomo-topográfico do tubo digestório das espécies Athene cunicularia (Strigiformes, Strigidae) e Tyto alba (Strigiformes, Tytonidae). PUBVET, Londrina, V. 6, N. 12, Ed. 199, Art. 1334, 2012.

"cólon" e Getty (1986) Schwarze (1980), que optaram por "reto". Estende-se da união ileocecal à cloaca, assim como relata Deem e Bennett (1996) e localiza-se na parte dorsal do quadrante caudal esquerdo da cavidade celômica, como cita este mesmo autor.

\section{CONCLUSÕES}

O tubo digestório apresenta poucas variações topográficas entre as duas espécies estudadas. Apresentam cecos desenvolvidos e ausência de inglúvio.

\section{REFERÊNCIAS}

ACCIOLY, A. M. R. Brasil 500 Pássaros. Local: Eletronorte - Centrais Elétricas do Norte do Brasil, 2000. Projeto.

ANDRADE, M. B.; SANTOS, A. L. Q.; CARVALHO, S. F. M.; BORGES, K. M.; OLEGÁRIO, M. M. M.; DIAS, E. A.; PEREIRA, R. V. V.; PEREIRA, P. C.; MIRANDA, R. L.; SILVA, C. B.; CASTRO, J. B.; ANDRADE, T. D.; COLICHINI, P. A. Descrição anatômica do tudo digestivo de Agapornis personata fischeri (PSITTACIDAE). In: ENCONTRO DE CIÊNCIAS AVÍCOLAS, 7., 2004, Uberlândia. Anais... Uberlândia: UFU. 2004, p. 13.

BARTON, N. W. H.; HOUSTON, D. C. Factors influencing the size of some internal organs in raptors. J. Raptor Res. v. 30, n. 4, p. 219-223, 1996.

BARTON, N. W. H.; HOUSTON, D. C. The incidence of intestinal parasites in british birds of prey. J. Raptor Res. v. 35, n. 1, p. 71-73, 2001.

BENNETT A. R.; DEEM, S. L. O sistema gastrointestinal das aves: I. Compêndio de Educação Continuada - para o Médico Veterinário, Florida, v. 1, n. 1, p. 50-56, 1996.

BORGES, K. M.; ANDRADE, M. B.; OLEGÁRIO, M. M. M.; SILVA, C. B.; CASTRO, J. B.; CARVALHO, S. F. M.; SANTOS, A. L. Q. Descrição anatômica do tubo digestivo de frango-d'água-azul (Porphyrula martinica - LINNAEUS, 1776). In: SEMANA ACADÊMICA DA UNIVERSIDADE FEDERAL DE UBERLÂNDIA, 1., 2004, Uberlândia. Anais... Uberlândia: UFU, 2004. 1CD-Rom.

COMITÊ BRASILEIRO DE REGISTROS ORNITOLÓGICOS. Listas das aves do Brasil. 10a edição de 25/01/2011. Disponível em <http://www.cbro.org.br>. Acesso em: 12 dez. 2011.

DEEM, S. L.; BENNETT A. R. O sistema gastrointestinal das Aves: II. Compêndio de Educação Continuada - para o Médico Veterinário, Florida, v. 1, n. 2, p. 118-123, 1996. 
DYCE, K. M.; SACK, W. O.; WENSING, C. J. G. Tratado de anatomia veterinária. 2 ed. Rio de Janeiro: Guanabara Koogan, 1997. 663 p.

DUKE, G. E. Digestão nas aves. In: DUKES, H. H. Dukes/Fisiologia dos animais domésticos. 11 ed. Rio de Janeiro: Guanabara Koogan, 1996. p. 390-397.

FREITAS, M. F. L. et al. Parásitos gastrointestinales de aves silvestres em cautiverio em el estado de Pernambuco, Brasil. Parasitologia Latinoamericana. Santiago, v. 57, n. 1-2. 2002.

JUNIPER, T.; PAN, M. Parrots - a guide to parrots of the world. New Haven: Yale University Press, 1998. 584 p.

MCLELLAND, J. Sistema digestivo das aves. In: GETTY, R. Sisson/Grossman: anatomia dos animais domésticos. $5^{\circ}$ ed. Rio de Janeiro: Guanabara Koogan, 1986. p. 1445-1464.

NICOLAU, A. A. et al. O sevofluorano em psitacídeos (Amazona aestiva). Determinação da dose mínima (D.A.M) para produção de anestesia geral. Ciência Rural, Santa Maria, v. 32, n. 5, 2002.

SCHWARZE, E. Compêndio de anatomia veterinária - anatomia de las aves. Zaragoza: Acribia, 1980. 212 p.

SMITH, B. J.; SMITH, S. A. Radiology. In: ALTMAN, R. B. et al. Avian medicine and surgery. Philadelphia: Saunders Company, p. 170-199.

SOUZA, A. G.; BORGES, K. M.; OLEGÁRIO, M. M. M.; ANDRADE, M. B.; PEREIRA, P. C.; SANTOS, A. L. Q.; VIEIRA, L. G. Descrição anatômica do tudo digestivo de periquito- australiano-azul (Melopsittacus undulatus). (FRINGILLIDAE). In: ENCONTRO SOBRE ANIMAIS SELVAGENS MANEJO E CONSERVAÇÃO, 3., 2005, Uberlândia. Resumos... Uberlândia: Universidade Federal de Uberlândia, 2005.

SOUZA, D. Todas as aves do Brasil. Guia de campo para identificação. Feira de Santana: Dall, 1998. 239 p. 